\title{
Radiations and female fertility
}

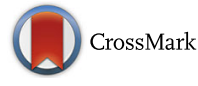

\author{
Roberto Marci ${ }^{1,2,3^{*}}$ (D), Maddalena Mallozzi ${ }^{4}$, Luisa Di Benedetto ${ }^{4}$, Mauro Schimberni ${ }^{4}$, Stefano Mossa ${ }^{5}$, llaria Soave ${ }^{4}$, \\ Stefano Palomba ${ }^{6}$ and Donatella Caserta ${ }^{4}$
}

\begin{abstract}
Hundreds of thousands of young women are diagnosed with cancer each year, and due to recent advances in screening programs, diagnostic methods and treatment options, survival rates have significantly improved. Radiation therapy plays an important role in cancer treatment and in some cases it constitutes the first therapy proposed to the patient. However, ionizing radiations have a gonadotoxic action with long-term effects that include ovarian insufficiency, pubertal arrest and subsequent infertility. Cranial irradiation may lead to disruption of the hypothalamic-pituitary-gonadal axis, with consequent dysregulation of the normal hormonal secretion. The uterus might be damaged by radiotherapy, as well. In fact, exposure to radiation during childhood leads to altered uterine vascularization, decreased uterine volume and elasticity, myometrial fibrosis and necrosis, endometrial atrophy and insufficiency. As radiations have a relevant impact on reproductive potential, fertility preservation procedures should be carried out before and/or during anticancer treatments. Fertility preservation strategies have been employed for some years now and have recently been diversified thanks to advances in reproductive biology. Aim of this paper is to give an overview of the various effects of radiotherapy on female reproductive function and to describe the current fertility preservation options.
\end{abstract}

Keywords: Radiotherapy, Radiation, Infertility, Fertility preservation

\section{Introduction}

In modern society people are frequently exposed to different types of radiations and this exposure comes form different sources. It could be either related to everyday life (e.g. televisions, mobile phones, computer devices, occupational equipment) or to the necessity of medical care (e.g. diagnostic imaging, interventional radiology procedures, anticancer therapy). Usually radiations are divided into two big subgroups, ionizing and non-ionizing, depending on the energy of the radiated particles.

\section{Non-ionizing radiations}

These type of radiations are basically electromagnetic fields (EMFs) that do not have enough energy to release electrons (non-ionizing), but are able to excite the movement of an electron to a higher energy state. Several classification of EMFs have been proposed, but generally 4 big subgroups are recognized $[1,2]$ :

\footnotetext{
* Correspondence: roberto.marci@unife.it

${ }^{1}$ Department of Morphology, Surgery and Experimental Medicine, University of Ferrara, via L. Borsari, 46, 44121 Ferrara, Italy

${ }^{2}$ Faculty of Medicine, University of Geneva, Geneva, Switzerland

Full list of author information is available at the end of the article
}

(i) extremely low frequency EMFs that have frequencies below $300 \mathrm{~Hz}$ (military equipment, railroads)

(ii) intermediate frequency EMFs characterized by frequencies ranging from $300 \mathrm{~Hz}$ to $10 \mathrm{MHz}$ (televisions, computer monitors, industrial cables)

(iii) hyper frequency EMFs characterized by frequencies ranging from $10 \mathrm{MHz}$ to $3000 \mathrm{GHz}$ (mobile phones, radio)

(iv) static EMFs that have zero frequency (MRI, geomagnetism)

The biological reaction of the human body to EMFs is still open to discussion, given the fact that many factors can influence the degree to which people may be affected (gender, body mass index, bone density, period of life, frequency and duration of the exposure) [3, 4]. EMFs have a high penetration power that could have disastrous consequences on tissues characterized by high concentrations of ions and electrons. Essentially the effects of non-ionizing radiations can be divided into thermal effects, caused by the heat generated by EMFs on a specific area, and non thermal effects, related to the absorption of the

(c) The Author(s). 2018 Open Access This article is distributed under the terms of the Creative Commons Attribution 4.0 International License (http://creativecommons.org/licenses/by/4.0/), which permits unrestricted use, distribution, and 
energy of the radiation [5]. Several studies have been published about the cytotoxicity of non-ionizing radiations, but most of them are based on animal models (rats) or on cell line cultures (fibroblasts, melanocytes, lymphocytes, monocytes, muscular cells) [6]. Concerning their effect on the female genital system, different studies on mice have shown that EMFs are able to prevent the formation of antral follicle [7], to inhibit ovulation and to reduce the total number of corpora lutea [8] and given their capacity to extend the lifetime of free radicals they favor cell apoptosis by increasing the oxidative stress resulting in DNA damage [9]. Some authors also observed that mice exposed to non-ionizing radiation have an increased number of macrophages in granulosa cells and lipid drops in theca cells [10]. Combined with the fact that an elevated number of macrophages has also been found in rats' growing follicles and corpora lutea, some authors postulate that EMFs exposure could accelerate apoptosis in ovarian cortical tissue (responsible for oocytes degeneration) [11]. Some studies conducted on pregnant women have focused on the effect of occupational exposure to video display terminals and pregnancy outcome: an elevated abortion rate and an increased number of birth defects have been found [12,13]. However, these results need to be carefully considered, because controversial conclusions have been obtained on animal models [14].

\section{lonizing radiations}

These are high energy radiations that are capable to knock electrons off an electron shell leaving the atoms with a net positive charge (ionization). The biological consequence on human cells of this electron strip is direct or indirect damage of cell's DNA. In case of a direct damage, the displaced electron breaks the DNA strand, where in case of an indirect damage the electron reacts with a water molecule resulting in the creation of free radicals that in the end damage the cell's DNA. A double-strand DNA break allows the potential for incorrect DNA repair leading to cell death or for symmetrical translocation, which could lead to the expression of an oncogene during cell replication or to abnormal division in gonads with potential hereditary disorders. The effects of ionizing radiations can be divided into two types:

(i) deterministic effects, which are dose-dependent. They take place only once the threshold has been exceeded and cause a functional impairment of a tissue/organ (e.g. impaired fertility related to altered ovarian function);

(ii) stochastic effects, which are the result of symmetrical translocation during cell replication. In this case there is no threshold level, but the odds of a stochastic effect to occur increases linearly with the dose (linear no-threshold hypothesis).
Charged particles, X-rays and gamma-rays represent ionizing radiations commonly used in medical care (diagnostic imaging and procedures, radiotherapy).

Given the extent of the topic, this review is focused on the most relevant clinical effects of radiotherapy on female fertility and on possible options for fertility preservation in young cancer survivors.

\section{Radiation therapy}

In Europe, 130,500 new cancer diagnoses (non-melanoma skin cancers being excluded) are made per year in prepubertal children and adolescents. The most common types of cancer occurring in this group of patients include lymphomas (21\%), melanomas (15\%), cancers of the male genital system (11\%), cancers involving the endocrine system $(11 \%)$ and cancers of the female genital tract $(9 \%)$ [15]. Nowadays, radiotherapy represents a cornerstone in cancer treatment and, in some cases, constitutes the first therapy proposed both to adolescents and young women ( $<45$ years old) with different tumors (e.g. sarcomas, medulloblastomas, advanced cervical cancer, rectal cancer, anal cancer and Hodgkin's lymphomas) [16, 17]. Several types of cancer may require radiation therapy before or after surgery. In women, pelvic irradiation can be recommended in case of cervical cancer, endometrial cancer, bladder cancer and rectal cancer, where cranio-spinal irradiation can be useful in case of central nervous system cancers or haematological malignancies (e.g. Hodgkin's disease). Total body irradiation is often required before bone marrow transplantation in Hodgkin's disease [18].

The impact of irradiation on reproductive potential depends on several factors, such as age of the patient, irradiation field, type, dose and duration of the treatment [19]. Pelvic irradiation affects both the ovary and the uterus and cranial irradiation could affect the hypothalamic-pituitary-gonadal axis. Even if reproductive organs' dysfunctions following radiation may be temporary, the recovery is often unpredictable and in some cases the damage could be permanent [20].

\section{Ovarian effects}

At birth, female ovaries contain approximately 1000,000 non-renewable primordial follicles, the number of which declines over time, primarily through apoptosis and atresia [9]. With age the number of human oocytes peaks at 6-7 million during fetal life (around midgestation) and decreases progressively in quantity and quality and does not regenerate. Approximately 1-2 million oocytes are present at birth, 30,0000-50,0000 at puberty, and 1000 at 51, which is the average age of menopause [21, 22]. Quantity and quality of a woman's oocytes can be influenced by several factors including genetics, lifestyle, environment, medical procedures and diseases (e.g. endometriosis, ovarian surgery, chemo- and radiotherapy). 
During radiotherapy, besides the tumor itself, the radiation field may also include healthy tissues close to the tumor that are unavoidably exposed to radiations. Although in some tissues the damage is reversible, in the ovary it is progressive and permanent. Radiation therapy is commonly applied because of its ability to control cell growth. Generally, cells with high mitotic activity and active DNA replication are more vulnerable to radiation-induced damage, whereas those with low mitotic division rates appear to be more resistant to it. However, oocytes seem to be an exception to this general rule: although arrested at the diplotene stage of the first meiotic division, they are extremely sensitive to radiations. In the past it was thought that the oocyte was not able to repair the genomic damage induced by ionizing radiations because of a lack in DNA repair mechanisms. However, recent studies conducted on animal models, have shown that mammalian oocytes have the enzymatic repair capacity to face and correct DNA modifications and that their radiosensitivity is closely linked to their degree of development [23, 24]. Human oocytes also express different DNA repair genes [25], but their function in the repair of radiation-induced genomic damage is still unclear. Indeed, radiotherapy has a profound impact on ovarian function, characterized by follicular atrophy and reduced follicle stores. This can hasten the natural decline of follicles number that therefore leads to impaired ovarian hormones production, uterine dysfunction due to inadequate estrogen exposure, early menopause and infertility $[22,26,27]$. The extent of the damage that occurs in the ovary depends on several factors such as age of the patient (the younger is the patient at the time of radiation, the greater is the damage), exposure dose, exposure time and eventually associated chemotherapy [28]. In prepubertal age the gonads are extremely vulnerable to radiations [22, 29 ]; it is estimated that $\leq 2$ Gy of radiation would destroy half of immature oocytes [30], while 25-50 Gy would produce infertility in a third of young women and in almost all women over 40 years of age [31-34] (Table 1).

Nevertheless, if only one side of the ovary is irradiated, ovarian dysfunction would occur in only half of all patients [35]. Furthermore, the risk of ovarian damage induced by gonadal tissue radiation exposure can be augmented when combined with alkylating chemotherapy drugs such as cyclophosphamide [36].

\section{Ovarian reserve assessment}

Ovarian reserve testing represents a cornerstone in counseling and selection of treatment in all patients who underwent gonadotoxic regimens. The ideal ovarian reserve test should be non-invasive, affordable, reproducible, rapidly interpretable with high specificity and little inter-/intracycle variability. At the present time, there is no perfect test and common methods to assess the ovarian reserve include:

i) dosage of follicle-stimulating hormone (FSH) and estradiol (E2) levels at day 3 of the menstrual cycle

ii) dosage of anti-mullerian hormone (AMH),

iii) transvaginal ultrasound (antral follicle count).

Day 3 FSH In case of impaired fertility, FSH is normally elevated. FSH an indirect measure of the ovarian reserve and is based on the negative feedback of FSH pituitary secretion. It has a higher inter-/intracycle variability and many studies agree that a normal FSH determination does not exclude ovarian dysfunction [37]. AMH measurement and antral follicle count (AFC) evaluation have been shown to have a higher predictive value when compared to day $3 \mathrm{FSH}$. To enhance its sensitivity it could be combined with E2 levels measurement [38].

AMH AMH is produced by the granulosa cells of early developing follicles and inhibits the transition from the primordial to the primary follicular stage. Its level is relatively independent of circulating gonadotropins concentration, allowing untimed testing. AMH production declines with age and results undetectable after menopause $[39,40]$. Among all ovarian tests it is considered the most stable throughout the menstrual cycle [40-43]. However, this issue remain still debated because some intracycle fluctuations have been reported in several

Table 1 Radiation doses and risk of gonadal failure (High risk: > 80\% sterilized; Mild risk: 20-80\% sterilized; Low risk: < 20\% sterilized)

\begin{tabular}{llll}
\hline Radiation Doses & Risk of Ovarian Failure & & \\
\cline { 2 - 4 } & Prepubertal girls & $15-40$ years & $>40$ years \\
\hline $\begin{array}{l}\text { Pelvic/abdominal irradiation } \\
<6 \text { Gy }\end{array}$ & Mild risk & No adverse effects & No adverse effects \\
15 Gy & High risk & Low risk & Mild risk \\
$25-50$ Gy & High risk & Mild risk & High risk \\
$50-80$ Gy & High risk & Mild risk & High risk \\
$>80$ Gy & High risk & High risk & High risk \\
Cranio-spinal irradiation $>25$ Gy & Mild risk & Mild risk & Mild risk \\
Total body irradiation & High risk & High risk & High risk \\
\hline
\end{tabular}


studies [44-46]. The main disadvantage of AMH testing is mainly related to the lack of a standardized international assay method that leads to high intra-/inter-assay variability (laboratory differences, sample stability and storage issues) [47]. Recently, in order to overcome this limitation and to improve precision and sensitivity of the test, new automated AMH assay platforms have been developed and are currently used in Europe and Asia [48].

Antral follicle count (AFC) Numerous studies have demonstrated the usefulness of transvaginal ultrasound, particularly at day 3 of the menstrual cycle. It provides two essential parameters that significantly correlate with ovarian reserve and fertility [49]: the measurement of the ovarian volume and the AFC, which defines the number of follicles between 2 and $10 \mathrm{~mm}$ in diameter. AFC is easy to carry out and provides immediate results with a good intercycle reliability. However, the precision of the measurement could be compromised by several factors such as differences in the criteria used for the evaluation of antral follicles, differences in ultrasound technology (resolution, 2D vs 3D) and ultrasound scans carried out by multiple sonographers with different degree of training [50, 51].

Nowadays, AMH testing represents the preferred biomarker to asses the ovarian reserve. In patients who underwent radiation therapy, AMH dosage before and after treatment is considered a useful tool in the selection of future fertility treatment. However, it should be taken into account that up to now there is no evidence that $\mathrm{AMH}$ pre-treatment levels can predict subsequent fertility and that the effect of different types of malignancies and treatment regimens on AMH level may vary considerably. Future research in this field is needed.

\section{Uterine effects, pregnancy outcomes and neonatal comorbidities}

Besides ovarian failure, also the uterus could be affected by radiotherapy and the consequent radiation-induced damage could be irreversible. In fact, exposure to radiation during childhood leads to altered uterine vascularization, decreased uterine volume and elasticity, myometrial fibrosis and necrosis, endometrial atrophy and insufficiency. Moreover, ulceration and necrosis last several months, and the damaged tissue may be replaced by dense collagen deposition. The cervix gets quite atrophic and loses its elasticity, especially in older patients $[52,53]$. In a study published by Larsen et al., the authors report that cytotoxic treatment during childhood does not affect adult uterine size, but, in contrast, uterine irradiation at young age reduces adult uterine volume. The reported results indicate that cancer survivors with spontaneous menstrual cycles have a diminished ovarian reserve. Therefore, reproductive dysfunctions may occur much earlier than anticipated [54].
In adults, an exposure to Total Body Irradiation (TBI) of $12 \mathrm{~Gy}$ is associated with significant uterine damage. During childhood, radiation doses of $>25$ Gy focused directly to the uterus appear to induce irreversible damage and so far, there is no consensus on the dose of radiation to the uterus, above which a pregnancy would not be sustainable [55]. In 2014 Teh et al. have suggested that patients receiving $>45$ Gy during adulthood and $>25$ Gy in childhood should be counseled to avoid pregnancies [52]. In fact, radiation could affect embryo implantation and, at the present time, uterine transplantation represent the only possible option for patients with childbearing desire, who underwent uterine radiation. Actually uterine transplantation is not routinely performed for medical and ethical reasons and until now it has been described only one live birth after this procedure [56]. Irradiation may lead to placental disorders (e.g. placenta accreta or placenta percreta), fetal malposition, preterm labor and premature delivery [56, 57]. Although rare, these alterations in uterine architecture can also increase the risk of uterine rupture [58]. Norwitz et al. showed reduced uterine volume and impaired uterine blood flow in a young woman who had a uterine rupture at 17 weeks of gestation. The patient had a remote history of total body irradiation for bone marrow transplantation for childhood leukemia. Although some radiation effects were observed, the severity of injuries was inferior as expected due to low doses of irradiation [59]. Mueller et al. compared the obstetric outcomes among female survivors of childhood and adolescent cancer to those of women without a history of cancer. The children of cancer survivors were more likely to be preterm and to weigh less than $2500 \mathrm{~g}$, while the risk of malformations or death were not increased [60]. Several studies demonstrated an increased risk of adverse pregnancy and neonatal outcomes associated with prior history of abdominal irradiation [22]. In a study published by Chiarelli et al. cancer patients receiving abdominopelvic radiation with or without surgery were more likely to have low birth weight infants and premature low birth weight infants, with higher perinatal mortality rates when compared to patients treated with surgery alone. Additionally, the likelihood of perinatal infant mortality and low birth weight were significantly related to the radiation dose [61]. The results reported by Signorello and colleagues in 2006 are in line with these findings. Authors report that the offspring of patients treated with high-dose radiotherapy have an increased risk of preterm delivery, low birth weight and small-for-gestational-age births when compared to offspring of patients who did not undergo radiotherapy [62]. In addition, in 2009 the British Cancer Survivor study concluded that female survivors of childhood cancer treated with abdominal radiotherapy have a 3 -fold increased risk of preterm delivery, a 2-fold increased risk of low birth weight and a small increased risk of miscarriage [63]. Green et al. reviewed the pregnancy outcome 
among childhood cancer survivors treated with radio- or chemotherapy [64]. One thousand nine hundred fifteen females with 4029 reported pregnancies were considered. Patients, whose ovaries where in the radiation field or close to it or shielded, showed a higher risk of miscarriage, although not statistically significant. Furthermore, the offspring of patients who received pelvic irradiation were more likely to weight $<2500 \mathrm{~g}$ at birth. In addition, several studies conducted on female survivors of Wilms tumor (WT) who underwent radiotherapy during childhood, analyzed the effect of low-dose flank irradiation on pregnancy and neonatal outcomes and demonstrated that they are at increased risk of preterm labor, fetal malposition, and premature delivery of low birth weight infants [65-70]. A recent study published in 2010 evaluated the impact of prior radiotherapy for unilateral WT on pregnancy outcomes [71]. Green and colleagues report that women who received flank radiation therapy during childhood are at increased risk of hypertension complicating pregnancy, fetal malposition, premature labor and that the offspring of these women are at risk for low birth weight at delivery $<<$ $2500 \mathrm{~g})$ and premature birth ( $<37$ weeks of gestation) [64].

\section{Hypothalamic-pituitary-gonadal axis effects}

Brain tumors constitute approximately $17 \%$ of all malignant tumors in patients younger than 20 years of age [72] and radiotherapy plays an important role in the curative and palliative treatment of patients with primary and/or metastatic brain tumors [73]. As survival rates of patients with childhood brain tumors have increased to $75 \%$, the side effects of cancer treatment are of particular importance [74]. Radiations induced anterior pituitary hormone deficiency represents the most common irreversible and progressive long-term complication of anticancer treatment and up to $50 \%$ of childhood cancer survivors will deal with an endocrinopathy requiring strict follow up to minimize the subsequent effects on growth, bone density, pubertal development and quality of life [75]. The hypothalamic-pituitary-gonadal axis (H-P-G axis) is a hormone system extremely vulnerable to radiotherapy; indeed, both brain surgery and cranial radiation could determine gonadotropin deficiency [76]. The exact mechanism by which radiations influence the H-P-G axis is still poorly understood. A direct injury to $\mathrm{H}-\mathrm{P}$ cells, rather than reduced hypothalamic blood flow seems to be the major cause of H-P-G axis dysfunction [77]. This hypothesis is supported by the fact that anterior pituitary hormone deficiencies follow a predictable pattern [78] where the growth hormone (GH) axis is the more radiosensitive (GH levels are reduced more than 90\% after irradiation), followed by gonadotropin, adrenocorticotropic hormone $(\mathrm{ACTH})$ and thyroid-stimulating hormone (TSH) axis. This is consistent with a direct radiation-induced selective hypothalamic neuronal and pituitary cell damage rather than a universal insult to the H-P axis [79, 80]. Furthermore, the evolution of these hormone deficiencies in time suggests possible delayed effects of radiotherapy on the development of secondary pituitary atrophy after hypothalamic damage [81-83].

The degree of neurotoxicity of radiation depends on total radiation dose, fraction size and duration of the radiation schedule. These variables determine the so called biological effective dose and as it increases, so does the risk of $\mathrm{H}-\mathrm{P}$ axis dysfunction [81, 83-85]. To minimize the risk, current irradiation regimens call for several fractions (with no more than 2Gy per fraction) spread out several days/weeks (with no more than 5 fractions per week) [86].

It is well known that the secretion of gonadotropin-releasing hormone $(\mathrm{GnRH}), \mathrm{FSH}$, luteinizing hormone (LH), estradiol, progesterone, and prolactin follows a pulsatile rhythm which is responsible for the reproductive hormonal environment [87]. Radiation-induced gonadotropin deficiency depends on irradiation dose and tumor location and has a wide spectrum of clinical manifestations, ranging from subclinical (detected only with GnRH testing) to severe forms. Clinically, significant gonadotropin deficiency is usually a late complication with a cumulative incidence of $20-50 \%$ on long-term follow-up, regardless of whether radiation was administered in childhood or during adulthood [86]. However, disturbances of the pulsatile rhythm of $\mathrm{FSH} / \mathrm{LH}$ production can affect fertility and libido and can disrupt the menstrual cycle.

Precocious puberty can occur after radiation doses of $<30$ Gy and it may be caused by a disinhibition of cortical influence on the hypothalamus. Studies on rats have shown that low irradiation doses (5-6 Gy) are associated with lower levels of inhibitory transmitter $\gamma$-aminobutyric-acid (GABA) and higher expression of GnRH in the pre-optic area $[88,89]$. Therefore, radiation-induced early puberty may be the result of a direct damage to the inhibitory GABA system with subsequent premature activation of $\mathrm{GnRH}$ neurons. In humans low irradiation doses (18-24 Gy) are associate with precocious puberty only in girls, where higher doses (25-50 Gy) affect both sexes equally [90, 91].

Hyperprolactinemia is another possible consequence of radiation therapy and is manly related to decreased levels of the inhibitory neurotransmitter dopamine. Mild to modest increase in PRL levels are mostly reported in adult females (20 to 50\%) after low radiation doses, but also children can be affected (5\% of the cases) [92]. Most of the time elevated levels of PRL do not have clinical manifestation, but occasionally may be responsible for amenorrhea and galactorrhea in women and for delayed puberty in children.

Despite optimal medical and surgical management of pituitary tumors, ovulation-induction therapy with gonadotropins is often required in these women [93]. In a 
recent questionnaire-based study published by Koustenis et al., the authors evaluated fertility characteristics in brain tumor survivors treated with brain irradiation. They found that patients receiving $\geq 30 \mathrm{~Gy}$, when compare to those who received 18-29 Gy or 0-17 Gy, reported less pregnancies and showed higher rates of permanent amenorrhea and infertility [94]. In a study published in 2002, Green et al. showed that the relative risk of miscarriage is increased in women who received cranial or craniospinal irradiation and in those patients where the ovaries were within or near the radiation field or within $5 \mathrm{~cm}$ of the field edge. On the other hand, the risk of miscarriage appears not to be higher when the ovaries are shielded [64]. Furthermore, these data also suggest that spinal irradiation could harm the pregnancy outcome, but further studies are needed to confirm these results.

\section{Fertility preservation options}

In patients diagnosed with cancer the main concern is, obviously, the treatment of the disease. However, given the increased number of young patients that undergo anticancer therapy, long-term side effects, including infertility, should be taken into account [19]. Before anticancer treatment, oncologists should discuss with their patients the consequences of surgery, radio- or chemotherapy, the infertility risk and the fertility preservation options, in order to established an effective, patient-tailored fertility preservation program [55]. Both chemo- and radiotherapy have a relevant impact on reproductive potential, thus fertility preservation procedures should be carried out before and/ or during these treatments. Fertility preservation requires a team effort. It should be managed by an oncology centre that has built a close collaboration between oncologists, fertility specialists, psychologists, and primary care physicians to allow early discussion and to offer a full range of options to these patients. Which method of fertility preservation a woman should choose depends on several factors, including the type of disease, the treatment required, the age of the patient, whether she has a long-term partner, and whether treatment can be delayed [95]. Around $70-75 \%$ of young cancer survivors are interested in parenthood, but the percentage of patients who undergo fertility preservation techniques before or during cancer treatment is significantly lower [96].

\section{Gonadal area shielding}

Shielding the gonadal area during total body irradiation is the standard procedure to reduce scatter radiation to reproductive organs [34]. In reproductive-aged women diagnosed with cancers requiring pre- or postoperative pelvic or craniospinal radiation, a safe and effective strategy to prevent premature ovarian failure and to optimize future fertility is Ovarian Transposition (OT) [97-99]. OT is a surgical procedure that transfers the ovaries outside the radiation field by suturing them within the paracolic gutter as high and as lateral as possible. It has been demonstrated that fixation of the ovaries of more than $1.5 \mathrm{~cm}$ above the iliac crest is the most important factor to preserve the ovaries [100]. The laparoscopic approach seems to be the preferred one, because it is associated to a more rapid recovery and less postoperative pain and has a success rate in preserving ovarian function of $88.6 \%$ [99]. However, the risk involved in the surgical procedure should not be underestimated. The most important complications are vascular injury, infarction of the fallopian tube, and ovarian cyst formation [101].

\section{Controlled ovarian stimulation}

Since young female patients' fertility may be impaired after radiotherapy, several other strategies have been proposed. Standard fertility preservation strategies, such as embryo and oocyte cryopreservation, have to be performed before anticancer therapy, but in some cases they may not be feasible (urgency to start cancer therapy, financial limitations, no access to specialized reproductive structures). One approach is to harvest oocytes, fertilize them in vitro, and deep-freeze (cryopreserve) the resulting embryos to be thawed and implanted later. Alternatively, oocytes can be frozen directly, although success rates are lower with this method. Another option is to obtain and cryopreserve directly a sample of ovarian tissue. If none of these is possible, oocytes may be obtained from a donor. If oocytes are to be harvested, there is not an optimal number of oocytes that should be retrieved, but cryopreservation of a large number of oocytes allows the clinician to perform multiple attempts at in vitro fertilization, improving the chances of pregnancy. So that more than one ripe egg can be obtained at a time, the patient must undergo a regimen of controlled ovarian stimulation (COS) to achieve multifollicular growth. There are several stimulation protocols, all based on giving pituitary hormones (e.g. agonist or antagonis of $\mathrm{GnRH}$ ). To promote follicular development recombinant FSH or human menopausal gonadotropin could be given. A single dose of human chorionic gonadotropin (hCG) is administered to induce ovulation when the lead follicles have reached 18 to $20 \mathrm{~mm}$ in size [102]. COS is considered very risky by many oncologists because it takes time and therefore delays anticancer therapy. Moreover, increased levels of circulating estrogens could be harmful in patients with hormone-sensitive cancers [103].

GH is an anabolic hormone with pleiotropic effects and some of its actions are mediated through enhancing serum and local (ovarian) IGF-1 levels and through direct $\mathrm{GH}$ receptor (GHR)-mediated effects on the ovary [104-106]. It is well known that GH has many implications in female fertility as many women with GH deficiency suffer a condition of subfertility and require assisted reproductive technologies to conceive. Indeed, 
poor responder patients with hypogonadotropic hypogonadism co-stimulated with GH showed higher fertilization and pregnancy rates [107-109]. Little is known about the specific molecular pathways implicated in $\mathrm{GH}$ effects on the ovary and its possible radioprotective role in ovarian damage induced by $\gamma$-irradiation in vivo. It seems that it may activate anti-oxidant systems in order to counteract the oxidative stress-mediated apoptosis [105, 110]. To date, the use of GH before, during or after radiotherapy is not recommended outside of clinical studies.

\section{Embryo cryopreservation}

Embryo cryopreservation is an established technology that provides a good success rate depending on number and quality of stored embryos [111]. Since a sperm sample is required for oocyte fertilization, the woman should have a partner before starting the treatment [55]. But when a woman is unmarried or does not have a long-time partner, mature oocyte cryopreservation represents another possible option. In fact, oocyte preservation represents a good option for all women who want to maintain their reproductive autonomy [55, 112]. Oocyte cryopreservation can be done either by conventional slow freezing or by vitrification [113, 114]. Vitrification is now the most widely used method due to the improved survival and fertilization rates, compared to the slow freezing method [114, 115]. Neither embryo nor oocyte cryopreservation can be performed in prepubertal girls [55]. Other disadvantages (mostly related to COS) of embryo and oocyte cryopreservation are:

i) risk of thromboembolic phenomena

ii) possible negative effect of COS on estrogensensitive tumors

iii) retrieval of a limited number of oocytes/embryos

iv) limited number of future in vitro fertilization (IVF) attempts.

Since in these patients there is generally a limited lapse of time for COS/IVF procedures before starting anticancer therapy, fertility specialists are often tempted to chose heavy stimulation protocols in order to retrieve the maximum number of oocytes. Such a decision should be taken with extreme caution as ovarian hyperstimulation syndrome (OHSS) in these women could be extremely dangerous and could further delay cancer treatment $[55,114$, 116]. Indeed, $\operatorname{COS}$ for embryo or mature oocyte cryopreservation should be recommended only if the medical condition of the patient allows to carry out the stimulation protocol and the retrieval procedure safely and if there is a fair chance of a good ovarian response. COS takes approximately 2 weeks from the 2nd day of the menstrual cycle, and the implications of delaying cancer therapy to complete the IVF procedure have to be taken into account
[55]. Random start of COS has been suggested in order to go beyond this limitation [117]. Furthermore, embryo cryopreservation has also ethical, legal and religious restrictions, especially concerning the disposal of embryos in case of patient death before embryo transfer [116].

\section{Oocytes cryopreservation}

Immature oocytes cryopreservation followed by in vitro maturation is a novel fertility preservation strategy that consists in collecting immature oocytes from primordial follicles (at the germinal vesicle stage) in unstimulated cycles and then letting them mature in vitro. To date, immature oocytes can be cryopreserved before or after in vitro maturation, but several studies have demonstrated that better results are obtained when vitrification follows the in vitro maturation process [118]. Compared with mature oocytes, immature oocytes are less susceptible to damage during cryopreservation and thus have a better chance of surviving freezing and thawing, thanks to some peculiar characteristics: they are small, have few organelles, lack a zona pellucida, have low metabolic activity, and are in a state of relative quiescence [119]. Since no ovarian stimulation is required, this technique allows to preserve fertility without delaying the onset of cancer treatment. This option could be considered when cancer treatment cannot be delayed for conventional follicular-phase retrieval [120] or in case of a premature LH surge during ovarian stimulation [121]. However, it is an experimental procedure that should be offered to patients only after proper counseling and as a part of a clinical study [122].

\section{Cryopreservation of ovarian tissue}

Another possible option to preserve fertility is the cryopreservation of ovarian tissue. It's a technique that consists in harvesting and freezing ovarian tissue, allowing the preservation of oocytes within primordial follicles [123]. Considering that women at age 30 have about 35 primordial follicles per square millimeter of ovarian tissue, 5 cubic fragments $5 \mathrm{~mm}$ wide may be sufficient to obtain more than 4000 primordial follicles [124]. In cases in which complete ovariectomy is necessary, it is possible to remove and cryopreserve fragments of normal ovarian tissue located at the margins of the surgical specimen. After cancer therapy, the ovarian tissue could be transplanted directly into the pelvis in its original location (orthotopic transplant) or outside the pelvis (e.g. fore-arm, subcutaneous abdominal area) (heterotopic transplant). With autotransplantation, there is a high risk of transmission of metastatic cancer cells. Blood-bone cancers such as leukemia and lymphomas are likely to be associated with the highest risk of ovarian metastasis through transplantation of thawed cryopreserved ovarian tissue. Histologic evaluation of ovarian samples before transplantation has been proposed to prevent cancer transmission, although it is not possible to 
completely abolish this risk [125, 126]. Spontaneous pregnancies can occur after orthotopic pelvic transplant, but IVF is necessary when a heterotopic transplant is carried out $[127,128]$. The first successful delivery after an orthotopic autotransplantation of ovarian cortical tissue was reported by Donnez et al. in 2004. The patient had a stage IV Hodgkin's lymphoma. Biopsy samples of ovarian cortex were taken before anticancer therapy and reimplanted 6 years later. Eleven months after transplantation a viable intrauterine pregnancy was confirmed by an hCG dosage and a transvaginal ultrasound [129]. Another successful delivery after transplantation of cryopreserved ovarian cortical tissue has been recently reported by Rodriguez-Wallberg et al. A 23 years-old woman, diagnosed with Ewing's sarcoma underwent chemo- (40 weeks intensive high-dose chemotherapy) and radiotherapy (54 Gy pelvic radiotherapy). After the treatment she developed a premature ovarian failure and at the age of 31 years-old she requested a re-transplantation because of childbearing desire. After an orthotopic transplantation the ovarian function promptly recovered and after COS 3 embryos of good quality were obtained. The pregnancy evolved normally and an healthy baby was delivered at term [130]. The first ongoing pregnancy from a heterotopic implantation of ovarian tissue has been reported by Stern et al. in a patient who had both ovaries removed. The tissue was transplanted to the anterior abdominal wall and two oocytes were retrieved after a mild stimulation protocol [131]. No live births have been reported so far in patients who cryopreserved ovarian tissue before puberty [55].

Cryopreservation of ovarian tissue has many advantages over oocyte and embryo cryopreservation:

i) it does not require prior ovarian stimulation with no delay in cancer treatment,

ii) there is no need for a partner or a sperm donor,

iii) it represents the only available option for prepubertal girls diagnosed with cancer,

iv) it preserves a larger pool of follicles and allows spontaneous resumption of the ovarian function [85]. Ovarian function generally resumes between 60 and 240 days post transplant and lasts for up to 7 years [132].

Despite significant advances, to date there have been fewer than 20 babies born worldwide through this method and currently ovarian tissue cryopreservation is still considered experimental and should be recommended only in carefully selected patients [133].

\section{Future directions}

Recent studies on animal models and in vitro differentiation have suggested mesenchimal stem cells (MSCs) as a possible new option for infertility treatment [134].
MSCs are pluripotent cells, which are able to differentiate into cells of all three germ layer including neuronal cells, osteocytes, chondrocytes, cardiac cells and germ cells $[135,136]$. Moreover they have the ability to secrete different growth factors that promote cell survival, proliferation and migration, as well as angiogenesis and immune modulation [137]. MSCs can be collected from different tissues such as bone marrow, umbilical blood, umbilical cord, amniotic fluid, peripheral blood, lung, liver and reproductive tissues $[138,139]$. Some studies report the presence on the surface epithelium of the ovaries of very small embryonic like cells (VSELs) that apparently can undergo asymmetric division and generate progenitor germinal cells [140]. The interaction between VSELs and MSCs may play a key role in infertility treatment. In fact, the intercommunication between these two lines of cells may promote the differentiation of MSCs into identical cells of the targeted tissue [141]. In a recent review published in 2018, the authors report that MSCs obtained from bone marrow and umbilical cord are the best candidates for the generation of functional gametes. However, these results should be considered carefully given the difficulty of comparing all the studies published so far (different evaluation methods and different MSCs sources) [142].

In vitro development of primordial follicles is another experimental technique that could further expand the panel of infertility treatment strategies. Previous studies on animal models have shown that primordial murine oocytes developed in vitro can be successfully fertilized and result in viable offspring $[143,144]$. In vitro growth and development of human oocytes has also been a matter of research. Telfer et al. demonstrated that activation and growth of human primordial follicles to antral stage is feasible [145] and other groups reported that isolated multi-laminar follicles can resume meiosis and reach Metaphase II [146, 147]. In a recent study published by McLaughlin et al. a new multistep culture system has been proposed in order to achieve complete oocyte development in vitro, from primordial oocytes to metaphase II oocytes [148]. Although a small number of immature oocytes reached Metaphase II, the results obtained in this study make conceivable the use of in vitro generated mature human oocytes for embryo production.

\section{Conclusion}

Modern society cannot avoid human exposure to various types of radiations both in everyday life and occupational activities. The effect of EMFs (non ionizing radiations) on human gametes and, more in general, on female fertility is still poorly understood, but it seems to correlate with higher miscarriage rates and birth defects. On the other hand, many women are exposed to ionizing radiations for medical reasons, both for diagnostic and therapeutic 
purpose. Radiation therapy can induce long-term side effects on reproductive organs that can impair pubertal development, hormonal regulation, and sexual function, affecting quality of life. Indeed, oocytes are extremely radiosentive and the subsequent depletion of follicle stores caused by radiations exposure may lead to premature ovarian failure, early menopause and infertility. Abdominal irradiation is also associated with alterations in uterine architecture (reduced myomietrial and cervical elasticity with endometrial atrophy/insufficiency) that correlate with several complications during pregnancy (placental disorders, fetal malposition, preterm labor and delivery, low birth weight, higher risk of uterine rupture). Cranio-spinal irradiation is often responsible for late complications on the H-P-G axis. Radiation dose and tumor location influence the wide spectrum of radiation-induced pituitary deficiencies that could range from subclinical manifestations (hyperprolactinemia with no clinical manifestation) to severe forms (precocious puberty, amenorrhea, galactorrhea, elevated abortion rates).

Over the past decade, the great progress in cancer diagnosis and treatment has led to a significant improvement in survival rates, making fertility preservation and quality of life after treatment a key issue, most of all in childhood cancers survivors that should be discussed before starting any radiotherapic treatments. Unfortunately, about $40 \%$ of cancer survivors report that they had no fertility counseling at the time of cancer diagnosis. At the present time, a consistent panel of fertility preservation strategies are available (gonadal area shielding, controlled ovarian stimulation, embryos, oocytes and ovarian tissue cryopreservation) and current research, mostly on animal models, is focused on developing further alternatives (mesenchimal stem cells, in vitro maturation of primordial follicles). A multidisciplinary collaboration between oncologists, radiotherapists, gynecologists and fertility specialists is required to improve awareness and availability of these fertility preservation options. Further studies on this field are needed in order to play out a patient-tailored strategy that could restore, when possible, the hormonal function and preserve the reproductive potential of the patient.

\section{Acknowledgements}

None.

Funding

Not applicable.

Availability of data and materials

Not applicable.

\section{Authors' contributions}

All authors contributed to the concepts of the manuscript. LDB, MS, SM and SP were involved in the literature search. RM, IS and MM designed the first draft of the article and further edited the manuscript. RM and DC proofread the final manuscript before submission. All authors read the manuscript critically and approved the final manuscript.
Ethics approval and consent to participate

Not applicable.

\section{Consent for publication}

Not applicable.

Competing interests

The authors declare that they have no competing interests.

\section{Publisher's Note}

Springer Nature remains neutral with regard to jurisdictional claims in published maps and institutional affiliations.

\section{Author details}

${ }^{1}$ Department of Morphology, Surgery and Experimental Medicine, University of Ferrara, via L. Borsari, 46, 44121 Ferrara, Italy. ${ }^{2}$ Faculty of Medicine, University of Geneva, Geneva, Switzerland. ${ }^{3}$ Division of Obstetrics and Gynecology, University Hospital of Geneva, Boulevard de la Cluse 30, 1205 Geneva, Switzerland. ${ }^{4}$ Department of Medical and Surgical Sciences and

Translational Medicine, Sant'Andrea Hospital, Faculty of Medicine and Psychology, University of Rome "Sapienza", Rome, Italy. "Radiation Oncology Unit, S Andrea Hospital, University Sapienza, Rome, Italy. ${ }^{6}$ Unit of Obstetrics and Gynecology, Grande Ospedale Metropolitano 'Bianchi - Melacrino Morelli', Reggio Calabria, Italy.

Received: 29 September 2017 Accepted: 24 October 2018 Published online: 16 December 2018

\section{References}

1. Juutilainen J. Developmental affects of electromagnetic fields. Bioelectromagnetics. 2005;26(Suppl 7):S107-15.

2. Gye MC, Park CJ. Effect of electromagnetic field, exposure on the reproductive system. Clin Exp Reprod Med. 2012;39(1):1-9.

3. Vesselinova L. Body mass index as a risk prediction and prevention factor for professional mixed lowintensity EMF burden. Electromagn Biol Med. 2015;34(3):238-43.

4. Tabrah FL, Ross P, Hoffmeier M, Gilbert F Jr. Clinical repot on long-term bone density after short-term EMF application. Bioelectromagnetics. 1998; 19(2):75-8.

5. SCENIHR. Potential health effects of exposure to electromagnetic fields. In: Scientific committee on emerging and newly identified health risks; 2015.

6. Heynick LN, Merritt JH. Radiofrequency fields and teratogenesis. Bioelectromagnetics. 2003:24(Suppl 6):S174-86.

7. Cecconi S, Gualtieri G, Di Bartolomeo A, Troiani G, Cifone MG, Canipari R. Evaluation of the effects of extremely low frequency electromagnetic fields on mammalian follicle development. Hum Reprod. 2000;15(11):2319-25.

8. Khaki A, Ranjbar M, Rahimi F, Ghahramanian A. The effects of electromagnetic field (EMFs) on ovary in rat. Ultrasound Obstet Gynecol. 2011:38:269.

9. Lai $H$, Singh NP. Magnetic-field-induced DNA strand breaks in brain cells of the rat. Environ Health Perspect. 2004;112(6):687-94.

10. Roshangar L, Soleimani RJ. Electron microscopic study of folliculogenesis after electromagnetic field exposure. J Reprod Infertil. 2004;5(4):299-307.

11. Soleimani Rad J, Rowshangar L, Karimi K. The effect of Electromagnetic field on Fallopian Tube. IFFS 2001 Selected Free Communication, Monduzzi Editore. Moelbourne: International Proceedings Division; 2001. p. 25-30.

12. Cao YN, Zhang Y, Liu Y. Effects of exposure to extremely low frequency electromagnetic fields on reproduction of female mice and development of offspring. Zhonghua Lao Dong Wei Sheng Zhi Ye Bing Za Zhi. 2006;24(8):468-70.

13. Goldhaber MK, Polen MR, Hiatt RA. The risk of miscarriage and birth defects among women who use visual display terminals during pregnancy. Am J Ind Med. 1988;13:695-706.

14. Chung MK, Lee SJ, Kim YB, Park SC, Shin DH, Kim SH, et al. Evaluation of spermatogenesis and fertility in $\mathrm{F} 1$ male rats after in utero and neonatal exposure to extremely low frequency electromagnetic fields. Asian J Androl. 2005;7(2):189-94.

15. Ferlay J, Soerjomataram I, Dikshit R, Eser S, Mathers C, Rebelo M, Parkin DM, Forman D, Bray F. Cancer incidence and mortality worldwide: sources, methods and major patterns in GLOBOCAN 2012. Int J Cancer. 2015;136(5): E359-86. 
16. Irtan S, Orbach D, Helfre S, Sarnacki S. Ovarian transposition in prepubescent and adolescent girls with cancer. Lancet Oncol. 2013;14(13):e601-8.

17. Jensen PT, Froeding LP. Pelvic radiotherapy and sexual function in women. Transl Androl Urol. 2015;4(2):186-205.

18. Meirow D, Nugent D. The effects of radiotherapy and chemotherapy on female reproduction. Hum Reprod Update. 2001;7(6):535-43.

19. Muñoz M, Santaballa A, Seguí MA, Beato C, de la Cruz S, Espinosa J, et al. SEOM clinical guideline of fertility preservation and reproduction in cancer patients (2016). Clin Transl Oncol. 2016;18(12):1229-36.

20. Biedka M, Kuźba-Kryszak T, Nowikiewicz T, Żyromska A. Fertility impairment in radiotherapy. Contemp Oncol (Pozn). 2016;20(3):199-204.

21. Archana KS, Kanika C, Rajrani S, Sanchita D. Ovarian volume and antral follicle count versus serum FSH measurement in assessment of ovarian reserve. IOSR-JDMS. 2017;16(4):44-7.

22. Wo JY, Viswanathan AN. The impact of radiotherapy on fertility, pregnancy, and neonatal outcomes in female cancer patients. Int J Radiat Oncol Biol Phys. 2009;73:1304-12.

23. Ashwood-Smith MJ, Edwards RG. DNA repair by oocytes. Mol Hum Reprod. 1996;2:46-51.

24. Adriaens I, Smitz J, Jacquet P. The current knowledge on radiosensitivity of ovarian follicle development stages. Hum Reprod Update. 2009;15:359-77.

25. Jaroudi S, Kakourou G, Cawood S, Doshi A, Ranieri DM, Serhal P, et al. Expression profiling of DNA repair genes in human oocytes and blastocysts using microarrays. Hum Reprod. 2009;24:2649-55.

26. Wallace $\mathrm{WH}$, Thomson AB, Kelsey TW. The radiosensitivity of the human oocyte. Hum Reprod. 2003;18(1):117-21.

27. Ogilvy-Stuart AL, Shalet SM. Effect of radiation on the human reproductive system. Environ Health Perspect. 1993;101:109-16.

28. Bath LE, Wallace WH, Critchley HO. Late effects of the treatment of childhood cancer on the female reproductive system and the potential for fertility preservation. BJOG. 2002;109(2):107-14

29. Gross E, Champetier C, Pointreau Y, Zaccariotto A, Dubergé T, Guerder C, et al. Normal tissue tolerance to external beam radiation therapy: ovaries. Cancer Radiother. 2010;14:373-5.

30. Wallace $\mathrm{WH}$, Thomson AB, Kelsey TW. The radiosensitivity of the human oocyte. Hum Reprod. 2003;18:117-21.

31. Royal College of Physicians of London. Management of Gonadal Toxicity Resulting from the Treatment of Adult Cancer: Report of a Working Party of the Joint Council for Clinical Oncology. London: JCCO; 1998.

32. Damewood MD, Grochow LB. Prospects for fertility after chemotherapy or radiation for neoplastic disease. Fertil Steril. 1986;45(4):443-59.

33. Chemaitilly W, Mertens AC, Mitby P, Whitton J, Stovall M, Yasui Y, et al. Acute ovarian failure in the childhood cancer survivor study. J Clin Endocrinol Metab. 2006;91(5):1723-8.

34. Rodriguez-Wallberg KA, Oktay K. Fertility preservation during cancer treatment: clinical guidelines. Cancer Manag Res. 2014;6:105-17.

35. Schuck A, Hamelmann V, Brämswing JH, Könemann S, Rübe C, Hesselmann S, et al. Ovarian function following pelvic irradiation in prepubertal and pubertal girls and young adult women. Strahelenther Onkol. 2005;181(8):534-9.

36. Loren AW, Mangu PB, Beck LN, Brennan L, Magdalinski AJ, Partridge AH, et al. Fertility preservation for patients with cancer: American Society of Clinical Oncology clinical practice guideline update. J Clin Oncol. 2013;31(19):2500-10.

37. Parker WH, Broder MS, Chang E, Feskanich D, Farquhar C, Liu Z, et al. Ovarian conservation at the time of hysterectomy and long-term health outcomes in the nurses' health study. Obstet Gynecol. 2009;113:1027-37.

38. Roudebush WE, Kivens WJ, Mattke JM. Estrogens (estradiol, E2) produce a negative feedback to the hypothalamus and anterior pituitary to inhibit FSH and LH secretion. Biomark Insights. 2008;3:259-68.

39. van Beek RD, van den Heuvel-Eibrink MM, Laven JS, de Jong FH, Themmen AP, Hakvoort-Cammel FG, et al. Anti-Mullerian hormone is a sensitive serum marker for gonadal function in women treated for Hodgkin's lymphoma during childhood. J Clin Endocrinol Metab. 2007;92(10):3869-74.

40. La Marca A, Broekmans FJ, Volpe A, Fauser BC, Macklon NS. Anti-Mullerian hormone (AMH): what do we still need to know? Hum Reprod. 2009;24(9): 2264-75.

41. Fanchin R, Taieb J, Lozano DH, Ducot B, Frydman R, Bouyer J. High reproducibility of serum anti-Mullerian hormone measurements suggests a multi-staged follicular secretion and strengthens its role in the assessment of ovarian follicular status. Hum Reprod. 2005;20(4):923-7.

42. Tsepelidis S, Devreker F, Demeestere I, Flahaut A, Gervy C, Englert Y. Stable serum levels of anti-Mullerian hormone during the menstrual cycle: a prospective study in normo-ovulatory women. Hum Reprod. 2007;22(7): 1837-40.

43. van Disseldorp J, Lambalk CB, Kwee J, Looman CW, Eijkemans MJ, Fauser $\mathrm{BC}$, et al. Comparison of inter- and intra-cycle variability of anti-Mullerian hormone and antral follicle counts. Hum Reprod. 2010;25(1):221-7.

44. Broer SL, Eijkemans MJ, Scheffer GJ, van Rooij IA, de Vet A, Themmen AP, et al. Anti-mullerian hormone predicts menopause: a long-term follow-up study in normoovulatory women. J Clin Endocrinol Metab. 2011;96(8):2532-9.

45. Freeman EW, Sammel MD, Lin H, Boorman DW, Gracia CR. Contribution of the rate of change of antimullerian hormone in estimating time to menopause for late reproductive-age women. Fertil Steril. 2012;98(5):1254-9.

46. Freeman EW, Sammel MD, Lin H, Gracia CR. Anti-mullerian hormone as a predictor of time to menopause in late reproductive age women. J Clin Endocrinol Metab. 2012;97(5):1673-80.

47. Broer SL, Broekmans FJ, Laven JS, Fauser BC. Anti-Mullerian hormone: ovarian reserve testing and its potential clinical implications. Hum Reprod Update. 2014;20(5):688-701.

48. van Helden J, Weiskirchen R. Performance of the two new fully automated anti-Mullerian hormone immunoassays compared with the clinical standard assay. Hum Reprod. 2015;30(8):1918-26.

49. BJ W. Ultrasound assessment of the ovary in the infertile woman. Semin Reprod Med. 2008;26(3):217-22.

50. Broer SL, Mol BW, Hendriks D, Broekmans FJ. The role of antimullerian hormone in prediction of outcome after IVF: comparison with the antral follicle count. Fertil Steril. 2009;91(3):705-14.

51. Broekmans FJ, Kwee J, Hendriks DJ, Mol BW, Lambalk CB. A systematic review of tests predicting ovarian reserve and IVF outcome. Hum Reprod Update. 2006;12(6):685-718.

52. Teh WT, Stern C, Chander S, Hickey M. The impact of uterine radiation on subsequent fertility and pregnancy outcomes. Biomed Res Int. 2014;2014:482968.

53. Dehghan T, Mozdarani H, Khoradmehr A, Kalantar SM. Effects of gamma radiation on fetal development in mice. Int J Reprod Biomed (Yazd). 2016; 14(4):247-54.

54. Larsen EC, Müller J, Schmiegelow K, Rechnitzer C, Andersen AN. Reduced ovarian function in long-term survivors of radiation- and chemotherapytreated childhood cancer. J Clin Endocrinol Metab. 2003:88(11):5307-14.

55. Mahajan N. Fertility preservation in female cancer patients: an overview. J Hum Reprod Sci. 2015:8(1):3-13.

56. Tang M, Webber K. Fertility and pregnancy in cancer survivors. Obstet Med. 2018;11:110-15.

57. Cohen LE. Cancer treatment and the ovary: the effects of chemotherapy and radiation. Ann N Y Acad Sci. 2008:1135:123-5.

58. Winther JF, JDJr B, Svendsen AL, Frederiksen K, Stovall M, Olsen JH. Spontaneous abortion in a Danish population-based cohort of childhood cancer survivors. J Clin Oncol. 2008;26:4340-6.

59. Norwitz ER, Stern HM, Grier H, Lee-Parritz A. Placenta percreta and uterine rupture associated with prior whole body radiation therapy. Obstet Gynecol. 2001;98:929-31.

60. Mueller BA, Chow EJ, Kamineni A, Daling JR, Fraser A, Wiggins CL, Mineau GP, et al. Pregnancy outcomes in female childhood and adolescent cancer survivors: a linked cancer-birth registry analysis. Arch Pediatr Adolesc Med. 2009;163(10):879-86

61. Chiarelli AM, Marrett LD, Darlington GA. Pregnancy outcomes in females after treatment for childhood cancer. Epidemiology. 2000;11(2):161-6.

62. Signorello LB, Cohen SS, Bosetti C, Stovall M, Kasper CE, Weathers RE, et al. Female survivors of childhood cancer: preterm birth and low birth weight among their children. J Natl Cancer Inst. 2006;98(20):1453-61.

63. Reulen RC, Zeegers MP, Wallace WH, Frobisher C, Taylor AJ, Lancashire ER, Winter DL, et al. Pregnancy outcomes among adult survivors of childhood cancer in the British childhood Cancer survivor study. Cancer Epidemiol Biomark Prev. 2009;18(8):2239-47.

64. Green DM, Whitton JA, Stovall M, Mertens AC, Donaldson SS, Ruymann FB, et al. Pregnancy outcome of female survivors of childhood cancer: a report from the childhood Cancer survivor study. Am J Obstet Gynecol. 2002; 187(4):1070-80

65. D'Angio GJ, Breslow N, Beckwith JB, Evans A, Baum H, deLorimier A, et al. Treatment of Wilms' tumor. Results of the third National Wilms' tumor study. Cancer. 1989;64(2):349-60.

66. D'Angio GJ, Evans A, Breslow N, Beckwith B, Bishop H, Farewell V, et al. The treatment of Wilms' tumor: results of the second National Wilms' tumor study. Cancer. 1981;47(9):2302-11. 
67. Green DM, Fine WE, Li FP. Offspring of patients treated for unilateral Wilms' tumor in childhood. Cancer. 1982:49(11):2285-8.

68. Hawkins MM, Smith RA. Pregnancy outcomes in childhood cancer survivors: probable effects of abdominal irradiation. Int J Cancer. 1989;43(3):399-402.

69. Hawkins MM, Winter DL, Burton HS, Potok MH. Heritability of Wilms' tumor. J Natl Cancer Inst. 1995;87(17):1323-4.

70. Sankila R, Olsen JH, Anderson H, Garwicz S, Glattre E, Hertz H, et al. Risk of cancer among offspring of childhood-cancer survivors. Association of the Nordic Cancer Registries and the Nordic Society of Paediatric Haematology and Oncology. N Engl J Med. 1998;338(19):1339-44.

71. Green DM, Lange JM, Peabody EM, Grigorieva NN, Peterson SM, Kalapurakal $J A$, et al. Pregnancy outcome after treatment for Wilms tumor: a report from the National Wilms Tumor Long-Term Follow-up Study. J Clin Oncol. 2010;28(17):2824-30

72. Viswanathan V, Pradhan KR, Eugster EA. Pituitary hormone dysfunction after proton beam radiation therapy in children with brain tumors. Endocr Pract. 2011;17(6):891-6.

73. Goodwin T, Delasobera BE, Fisher PG. Reproductive health issues in survivors of childhood and adult brain tumors. Cancer Treat Res. 2009;150: 215-22.

74. Lawrence YR, Li XA, el Naqa I, Hahn CA, Marks LB, Merchant TE, et al. Radiation dose-volume effects in the brain. Int J Radiat Oncol Biol Phys. 2010;76:520-7.

75. Crowne E, Gleeson H, Benghiat H, Sanghera P, Toogood A. Effect of cancer treatment on hypothalamic-pituitary function. Lancet Diabetes Endocrinol. 2015;3(7):568-76.

76. Barnes N, Chemaitilly W. Endocrinopathies in survivors of childhood neoplasia. Front Pediatr. 2014;2:101.

77. Chieng PU, Huang TS, Chang CC, Chong PN, Tien RD, Su CT. Reduced hypothalamic blood flow after radiation treatment of nasopharyngeal cancer: SPECT studies in 34 patients. Am J Neuroradiol. 1991;12:661-5.

78. Littley MD, Shalet SM, Beardwell CG, Robinson EL, Sutton ML. Radiationinduced hypopituitarism is dose-dependent. Clin Endocrinol. 1989;31: 363-73.

79. Hochberg Z, Kuten A, Hertz P, Tatcher M, Kedar A, Benderly A. The effect of single-dose radiation on cell survival and growth hormone secretion by rat anterior pituitary cells. Radiat Res. 1983;94:508-12.

80. Robinson IC, Fairhall KM, Hendry JH, Shalet SM. Differential radiosensitivity of hypothalamopituitary function in the young adult rat. J Endocrinol. 2001; 169:519-26.

81. Clayton PE, Shalet SM. Dose dependency of time of onset of radiationinduced growth hormone deficiency. J Pediatr. 1991;118:226-8.

82. Schmiegelow M, Lassen S, Poulsen HS, Feldt-Rasmussen U, Schmiegelow $\mathrm{K}$, Hertz $\mathrm{H}$, et al. Cranial radiotherapy of childhood brain tumours: growth hormone deficiency and its relation to the biological effective dose of irradiation in a large population based study. Clin Endocrinol. 2000;53:191-7.

83. Spoudeas HA, Hindmarsh PC, Matthews DR, Brook CG. Evolution of growth hormone neurosecretory disturbance after cranial irradiation for childhood brain tumours: a prospective study. J Endocrinol. 1996;150: 329-42.

84. Duffner PK, Cohen ME, Voorhess ML, MacGillivray MH, Brecher ML, Panahon A, et al. Long-term effects of cranial irradiation on endocrine function in children with brain tumors. A prospective study. Cancer. 1985;56:2189-93.

85. Lam KSL, Tse VKC, Wang C, Yeung RTT, Ho JHC. Effects of cranial irradiation on hypothalamic-pituitary function-a 5-year longitudinal study in patients with nasopharyngeal carcinoma. Q J Med. 1991;78:165-76.

86. Darzy KH, Shalet SM. Hypopituitarism following radiotherapy revisited. Endocr Dev. 2009;15:1-24.

87. Veldhuis JD. The hypothalamic pulse generator: the reproductive core. Clin Obstet Gynecol. 1990;33(3):538-50,

88. Roth C, Schmidberger H, Schaper O, Leonhardt S, Lakomek M, Wuttke W, et al. Cranial irradiation of female rats causes dose-dependent and agedependent activation or inhibition of pubertal development. Pediatr Res. 2000;47:586-91.

89. Roth $\mathrm{C}$, Lakomek M, Schmidberger $\mathrm{H}$, Jarry $\mathrm{H}$. Cranial irradiation induces premature activation of the gonadotropin-releasing-hormone (in German). Klin Pediatr. 2001;213:239-43.

90. Ogilvy-Stuart AL, Clayton PE, Shalet SM. Cranial irradiation and early puberty. J Clin Endocrinol Metab. 1994;78:1282-6.
91. Lannering B, Jansson C, Rosberg S, Albertsson-Wikland K. Increased LH and FSH secretion after cranial irradiation in boys. Med Pediatr Oncol. 1997;29: 280-7.

92. Rappaport R, Brauner R, Czernichow P, Thibaud E, Renier D, Zucker JM, et al. Effect of hypothalamic and pituitary irradiation on pubertal development in children with cranial tumors. J Clin Endocrinol Metab. 1982:54:1164-8.

93. Hirshfeld-Cytron J, Kim HH. Treatment of infertility in women with pituitary tumors. Expert Rev Anticancer Ther. 2006;6:S55-62.

94. Koustenis E, Pfitzer C, Balcerek M, Reinmuth S, Zynda A, Stromberger C, et al. Impact of cranial irradiation and brain tumor location on fertility: a survey. Klin Padiatr. 2013;225(6):320-4.

95. Soave I, Lo Monte G, Giugliano E, Graziano A, Marci R. Preserving fertility in female cancer patients: a snapshot of the options. Cleve Clin J Med. 2013; 80(5):309-17.

96. Linkeviciute A, Boniolo G, Chiavari L, Peccatori FA. Fertility preservation in cancer patients: the global framework. Cancer Treat Rev. 2014;40(8):1019-27.

97. Clough KB, Goffinet F, Labib A, Renolleau C, Campana F, de la Rochefordiere A, et al. Laparoscopic unilateral ovarian transposition prior to irradiation: prospective study of 20 cases. Cancer. 1996;77:2638-45.

98. Mossa B, Schimberni M, Di Benedetto L, Mossa S. Ovarian transposition in young women and fertility sparing. Eur Rev Med Pharmacol Sci. 2015;19(18): 3418-25.

99. Arian SE, Goodman L, Flyckt RL, Falcone T. Ovarian transposition: a surgical option for fertility preservation. Fertil Steril. 2017;107(4):e15.

100. Hwang JH, Yoo HJ, Park SH, Lim MC, Seo SS, Kang S, et al. Association between the location of transposed ovary and ovarian function in patients with uterine cervical cancer treated with (postoperative or primary) pelvic radiotherapy. Fertil Steril. 2012;97:1387-93.

101. Terenziani M, Piva L, Meazza C, Gandola L, Cefalo G, Merola M. Oophoropexy: a relevant role in preservation of ovarian function after pelvic irradiation. Fertil Steril. 2009;91:935.e15-6.

102. Goldberg JM, Falcone T, Attaran M. In vitro fertilization update. Cleve Clin J Med. 2007;74:329-38.

103. Prest SJ, May FE, Westley BR. The estrogen-regulated protein, TFF1, stimulates migration of human breast cancer cells. FASEB J. 2002;6:592-4.

104. Herrington J, Carter-Su C. Signaling pathways activated by the growth hormone receptor. Trends Endocrinol Metab. 2001;12:252-7.

105. Mahran YF, El-Demerdash E, Nada AS, El-Naga RN, Ali AA, Abdel-Naim AB. Growth hormone ameliorates the radiotherapy-induced ovarian follicular loss in rats: impact on oxidative stress, apoptosis and IGF-1/IGF-1R Axis. PLoS One. 2015;10(10):e0140055.

106. Bondy CA, Zhou J, Arraztoa JA. Growth Hormone, Insulin-Like Growth Factors, and the Ovary. In: Wassarman P, Neill JD, EL Sevier. Knobil and Neill's physiology of reproduction London:2005. p. 527-540.

107. Homburg R, Ostergard H. Clinical applications of growth hormone for ovarian stimulation. Hum Reprod Update. 1995;1:264-75.

108. Kucuk K, Kozinoglu H, Ayten K. Growth hormone co-treatment within a GnRH agonist long protocol in patients with poor ovarian response: a prospective, randomized, clinical trial. J Assist Reprod Genet. 2008:25(4):1237.

109. de Boer JA, Schoemaker J, van der Veen EA. Impaired reproductive function in women treated for growth hormone deficiency during childhood. Clin Endocrinol. 1997:46(6):681-9.

110. Baeza I, Fdez-Tresguerres J, Ariznavarreta C, De la Fuente M. Effects of growth hormone, melatonin, oestrogens and phytoestrogens on the oxidized glutathione (GSSG)/reduced glutathione (GSH) ratio and lipid peroxidation in aged ovariectomized rats. Biogerontology. 2010;11:687-701.

111. Pavone ME, Confino R, Steinberg M. Female fertility preservation: a clinical perspective. Minerva Ginecol. 2016;68(4):458-65.

112. Noyes N, Knopman JM, Melzer K, Fino ME, Friedman B, Westphal LM. Oocyte cryopreservation as a fertility preservation measure for cancer patients. Reprod BioMed Online. 2011;23(3):323-33.

113. Fadini R, Brambillasca F, Renzini MM, Merola M, Comi R, De Ponti E, et al. Human oocyte cryopreservation: comparison between slow and ultrarapid methods. Reprod BioMed Online. 2009;19(2):171-80.

114. Batuhan O, Safaa AH. Techniques for ovarian tissue, whole ovary, oocyte and embryo cryopreservation. J Reprod Infertil. 2010;11(1):3-15.

115. Chian RC, Wang Y, Li YR. Oocyte vitrification: advances, progress and future goals. J Assist Reprod Genet. 2014;31(4):411-20.

116. Zoloth L, Henning AA. Bioethics and Oncofertility: arguments and insights from religious traditions. Cancer Treat Res. 2010;156:261-78. 
117. Cakmak H, Katz A, Cedars MI, Rosen MP. Effective method for emergency fertility preservation: random-start controlled ovarian stimulation. Fertil Steril. 2013;100(6):1673-80.

118. Cao Y, Xing Q, Zhang ZG, Wei ZL, Zhou P, Cong L. Cryopreservation of immature and in vitro-matured human oocytes by vitrification. Reprod BioMed Online. 2009;19:369-73.

119. Toth TL, Baka SG, Veeck LL, Jones HW Jr, Muasher S, Lanzendorf SE. Fertilization and in vitro development of cryopreserved human prophase I oocytes. Fertil Steril. 1994;61:891-4.

120. Maman E, Meirow D, Brengauz M, Raanani H, Dor J, Hourvitz A. Luteal phase oocyte retrieval and in vitro maturation is an optional procedure for urgent fertility preservation. Fertil Steril. 2011;95:64-7.

121. Oktay K, Demirtas E, Son WY, Lostritto K, Chian RC, Tan SL. In vitro maturation of germinal vesicle oocytes recovered after premature luteinizing hormone surge: description of a novel approach to fertility preservation. Fertil Steril. 2008;89:228.e19-22.

122. Walls ML, Douglas K, Ryan JP, Tan J, Hart R. In-vitro maturation and cryopreservation of oocytes at the time of oophorectomy. Gynecol Oncol Rep. 2015;13:79-81.

123. Anderson RA, Wallace WHB, Telfer EE. Ovarian tissue cryopreservation for fertility preservation: clinical and research perspectives. Human Reproduction Open. 2017;(1). https://doi.org/10.1093/hropen/hox001.

124. Martinez-Madrid B, Dolmans MM, Van Langendonckt A, Defrère S, Donnez J. Freeze-thawing intact human ovary with its vascular pedicle with a passive cooling device. Fertil Steril. 2004;82:1390-4.

125. Practice Committee of American Society for Reproductive Medicine; Practice Committee of Society for Assisted Reproductive Technology. Ovarian tissue and oocyte cryopreservation. Fertil Steril. 2008;90:\$241-6.

126. Oktay K. Ovarian tissue cryopreservation and transplantation: preliminary findings and implications for cancer patients. Hum Reprod Update. 2001;7:526-34.

127. Donnez J, Jadoul P, Squifflet J, Van Langendonckt A, Donnez O, Van Eyck AS, et al. Ovarian tissue cryopreservation and transplantation in cance patients. Best Pract Res Clin Obstet Gynaecol. 2010;24(1):87-100.

128. Morris SN, Ryley D. Fertility preservation: nonsurgical and surgical options. Semin Reprod Med. 2011;29(2):147-54.

129. Donnez J, Dolmans MM, Demylle D, Jadoul P, Pirard C, Squifflet J, et al. Livebirth after orthotopic transplantation of cryopreserved ovarian tissue. Lancet. 2004;364(9443):1405-10.

130. Rodriguez-Wallberg KA, Karlström PO, Rezapour M, Castellanos E, Hreinsson J, Rasmussen C, et al. Full-term newborn after repeated ovarian tissue transplants in a patient treated for Ewing sarcoma by sterilizing pelvic irradiation and chemotherapy. Acta Obstet Gynecol Scand. 2015;94(3):324-8.

131. Stern CJ, Gook D, Hale LG, Agresta F, Oldham J, Rozen G, et al. First reported clinical pregnancy following heterotopic grafting of cryopreserved ovarian tissue in a woman after a bilateral oophorectomy. Hum Reprod. 2013;28(11):2996-9.

132. Kim SS. Assessment of long term endocrine function after transplantation of frozen-thawed human ovarian tissue to the heterotopic site: 10 year longitudinal follow-up study. J Assist Reprod Genet. 2012;29(6):489-93.

133. Donnez J, Silber S, Andersen CY, Demeestere I, Piver P, Meirow D, et al. Children born after autotransplantation of cryopreserved ovarian tissue. A review of 13 live births. Ann Med. 2011;43:437-50.

134. Cyranoski D. Stem cells boom in vet clinics. Nature. 2013:496(7444):148-9.

135. Patel DM, Shah J, Srivastava AS. Therapeutic potential of mesenchymal stem cells in regenerative medicine. Stem Cells Int. 2013;2013:496218.

136. Fazeli Z, Omrani MD, Ghaderian SM. CD29/ CD184 expression analysis provides a signature for identification of neuronal like cells differentiated from PBMSCs. Neurosci Lett. 2016;630:189-93.

137. Liang X, Ding Y, Zhang Y, Tse HF, Lian Q. Paracrine mechanisms of mesenchymal stem cell-based therapy: current status and perspectives. Cell Transplant. 2014;23(9):1045-59.

138. da Silva Meirelles L, Chagastelles PC, Nardi NB. Mesenchymal stem cells reside in virtually all post-natal organs and tissues. J Cell Sci. 2006;119:2204-13.

139. Fazeli Z, Rajabibazl M, Salami S, Vazifeh Shiran N, Ghaderian SMH, Omrani MD. Gene expression profile of adherent cells derived from human peripheral blood: evidence of mesenchymal stem cells. J Sci Islam Repub Iran. 2016;27(2):105-12.

140. Chikhovskaya JV, Jonker MJ, Meissner A, Breit TM, Repping S, van Pelt AM Human testis-derived embryonic stem cell-like cells are not pluripotent, but possess potential of mesenchymal progenitors. Hum Reprod. 2012; 27(1):210-21.
141. Dezawa M. Muse cells provide the pluripotency of mesenchymal stem cells: direct contribution of muse cells to tissue regeneration. Cell Transplant. 2016;25(5):849-61.

142. Fazeli Z, Abedindo A, Omrani MD, Ghaderian SMH. Mesenchymal stem cells (MSCs) therapy for recovery of fertility: a systematic review. Stem Cell Rev. 2018;14(1):1-12

143. Eppig JJ, O'Brien MJ. Development in vitro of mouse oocytes from primordial follicles. Biol Reprod. 1996;54:197-207.

144. O'Brien MJ, Pendola JK, Eppig JJ. A revised protocol for in vitro development of mouse oocytes from primordial follicles dramatically improves their developmental competence. Biol Reprod. 2003;68:1682-6.

145. Telfer EE, McLaughlin M, Ding C, Thong KJ. A two-step serum-free culture system supports development of human oocytes from primordial follicles in the presence of activin. Hum Reprod. 2008;23:1151-8.

146. Xiao S, Zhang J, Romero MM, Smith KN, Shea LD, Woodruff TK. In vitro follicle growth supports human oocyte meiotic maturation. Sci Rep. 2015;5:17323.

147. Xu M, Barrett SL, West-Farrell E, Kondapalli LA, Kiesewetter SE, Shea LD, et al. In vitro grown human ovarian follicles from cancer patients support oocyte growth. Hum Reprod. 2009;24:2531-40.

148. McLaughlin M, Albertini DF, Wallace WHB, Anderson RA, Telfer EE. Metaphase II oocytes from human unilaminar follicles grown in a multi-step culture system. Mol Hum Reprod. 2018. https:/doi.org/10.1093/molehr/gay002.

\section{Ready to submit your research? Choose BMC and benefit from:}

- fast, convenient online submission

- thorough peer review by experienced researchers in your field

- rapid publication on acceptance

- support for research data, including large and complex data types

- gold Open Access which fosters wider collaboration and increased citations

- maximum visibility for your research: over $100 \mathrm{M}$ website views per year

At BMC, research is always in progress.

Learn more biomedcentral.com/submissions 